Luise Abramowski

Neue christologische Untersuchungen 
Berlin-Brandenburgische Akademie der Wissenschaften

Texte und Untersuchungen zur Geschichte der altchristlichen Literatur (TU)

Archiv für die Ausgabe der Griechischen Christlichen Schriftsteller der ersten Jahrhunderte

Begründet von

O. von Gebhardt und A. von Harnack

Herausgegeben von

Christoph Markschies

\section{Band 187}

berlin-brandenburgische AKADEMIE DER WISSENSCHAFTEN 


\section{Luise Abramowski Neue christologische Untersuchungen}

Bearbeitet von Alexander Schilling

Herausgegeben von Volker Henning Drecoll, Hanns Christof Brennecke und Christoph Markschies

\section{DE GRUYTER}


Herausgegeben durch die

Berlin-Brandenburgische Akademie der Wissenschaften

von Christoph Markschies

ISBN 978-3-11-064492-0

e-ISBN (PDF) 978-3-11-064741-9

ISSN 0082-3589

\section{Library of Congress Control Number: 2019930903}

\section{Bibliografische Information der Deutschen Nationalbibliothek}

Die Deutsche Nationalbibliothek verzeichnet diese Publikation in der Deutschen National-

bibliografie; detaillierte bibliografische Daten sind im Internet über http://dnb.dnb.de abrufbar.

(C) 2021 Walter de Gruyter GmbH, Berlin/Boston

Satz: Dörlemann Satz, Lemförde

Druck und Bindung: CPI books GmbH, Leck

www.degruyter.com 